\title{
Preliminary stratigraphic interpretations of the Soledad Rojo formation in the lower Colorado River Extensional Corridor, western Palo Verde Mountains, southeastern California \\ Bryan P. Murray \& Abdulla Al-kaabi
}

Department of Geological Sciences, California State Polytechnic University, Pomona

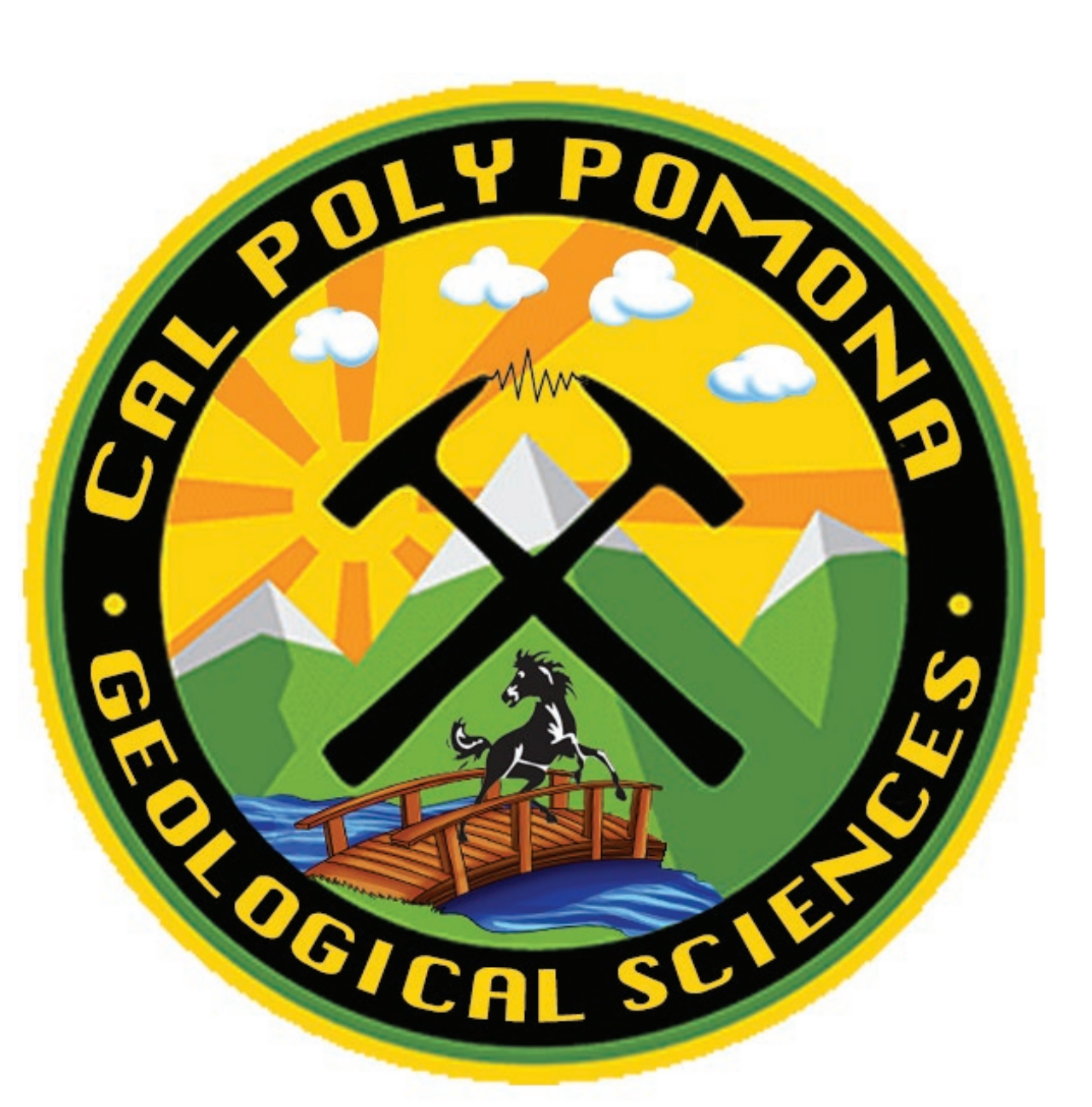

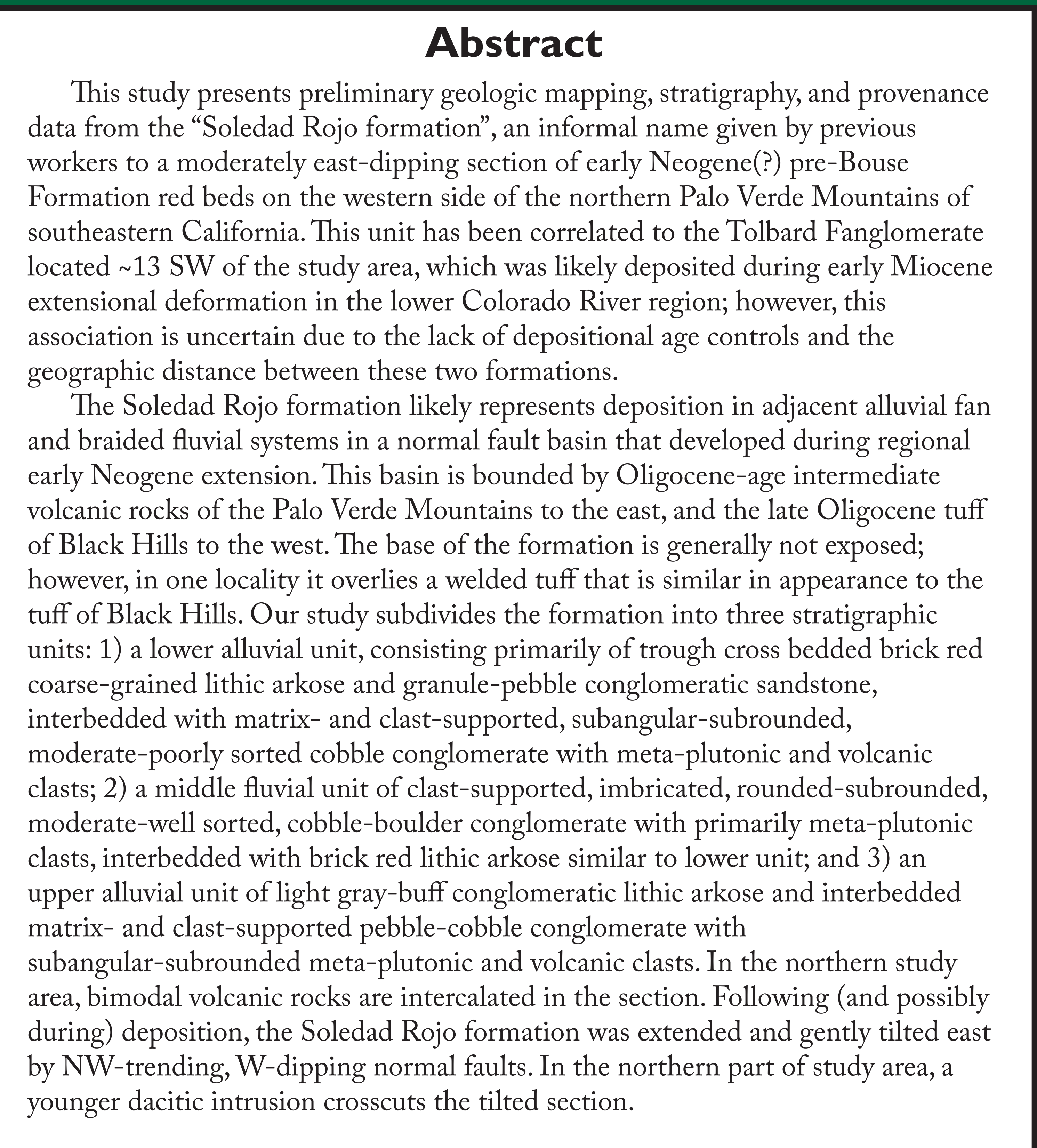
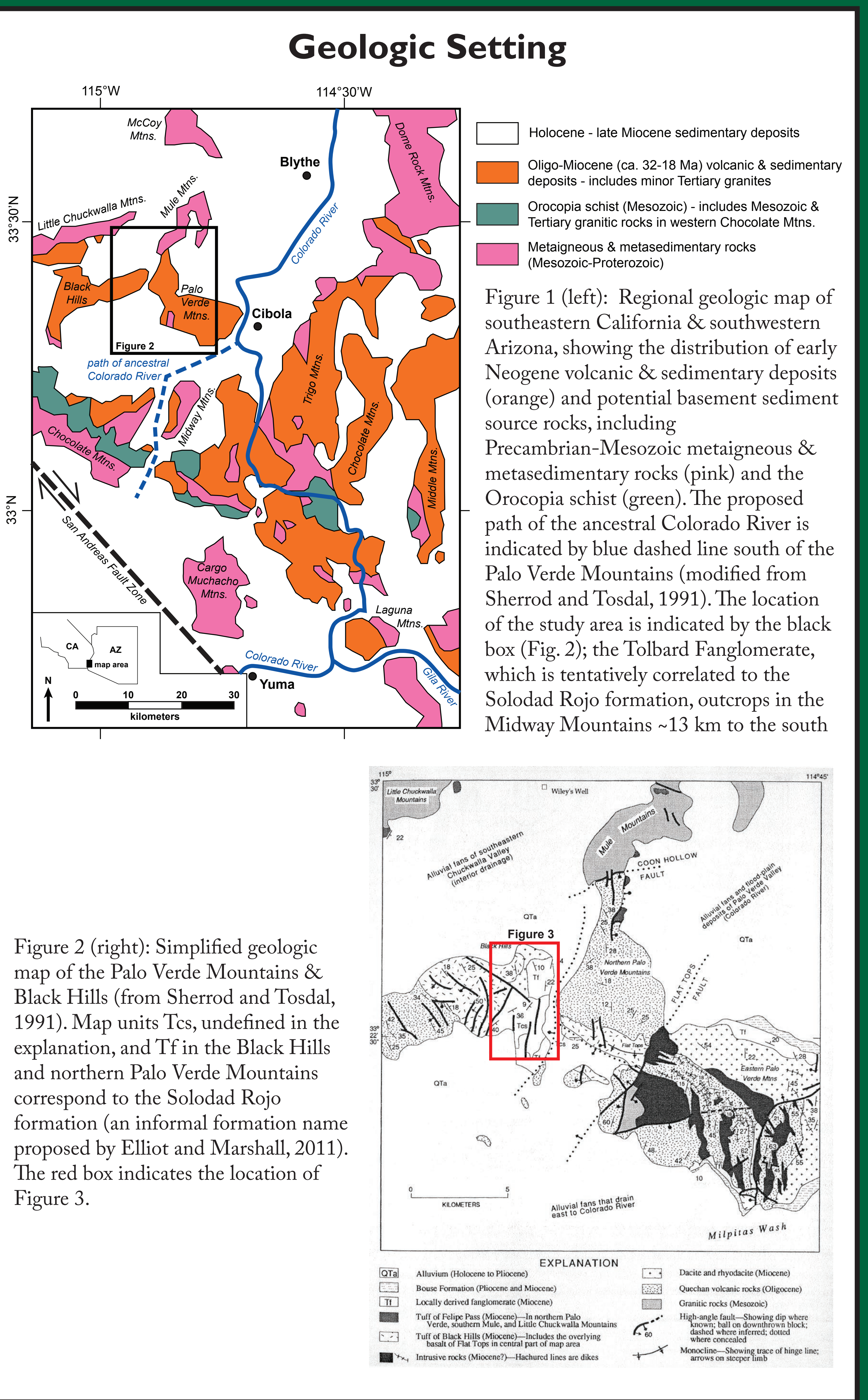
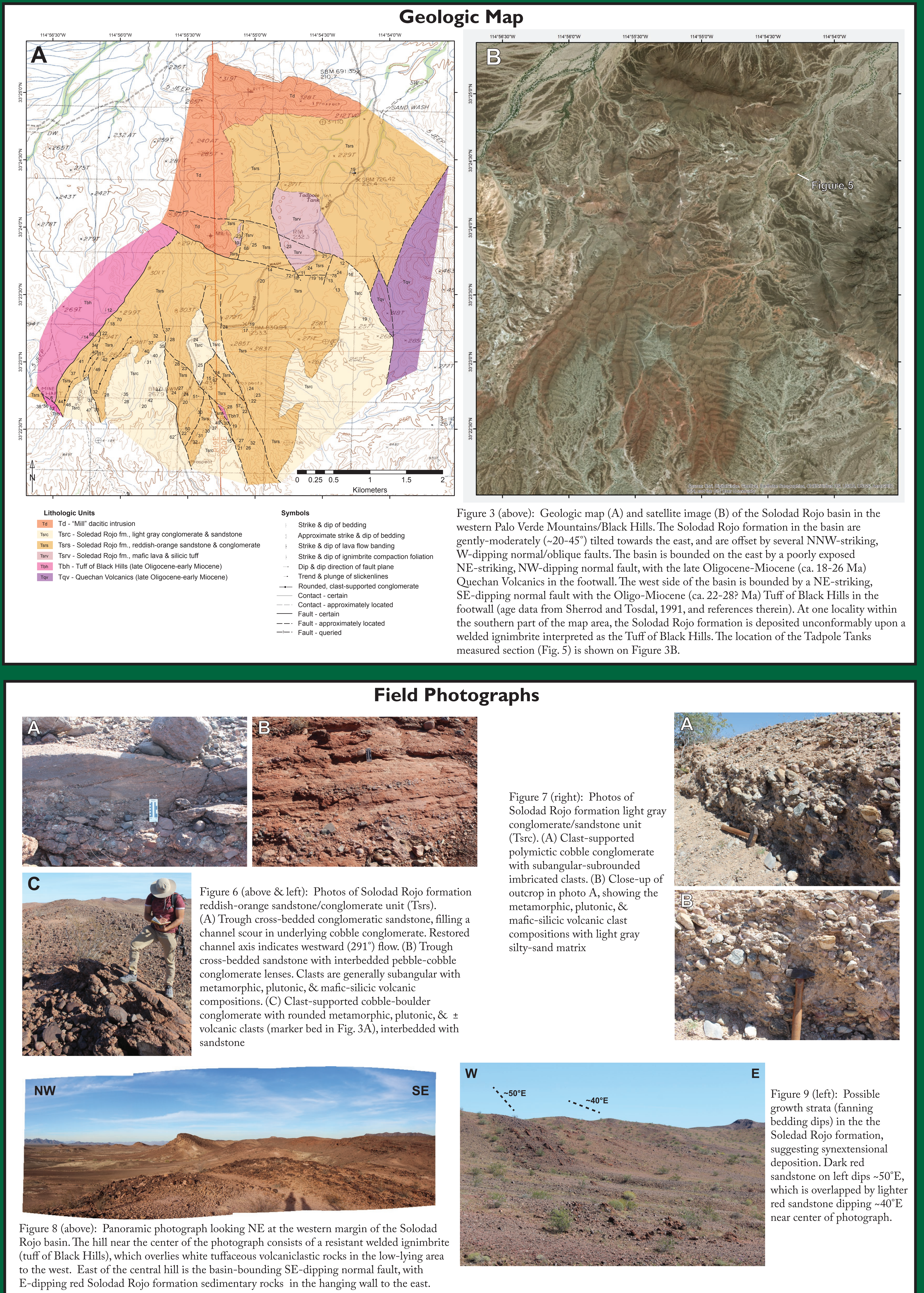



Preliminary Interpretations

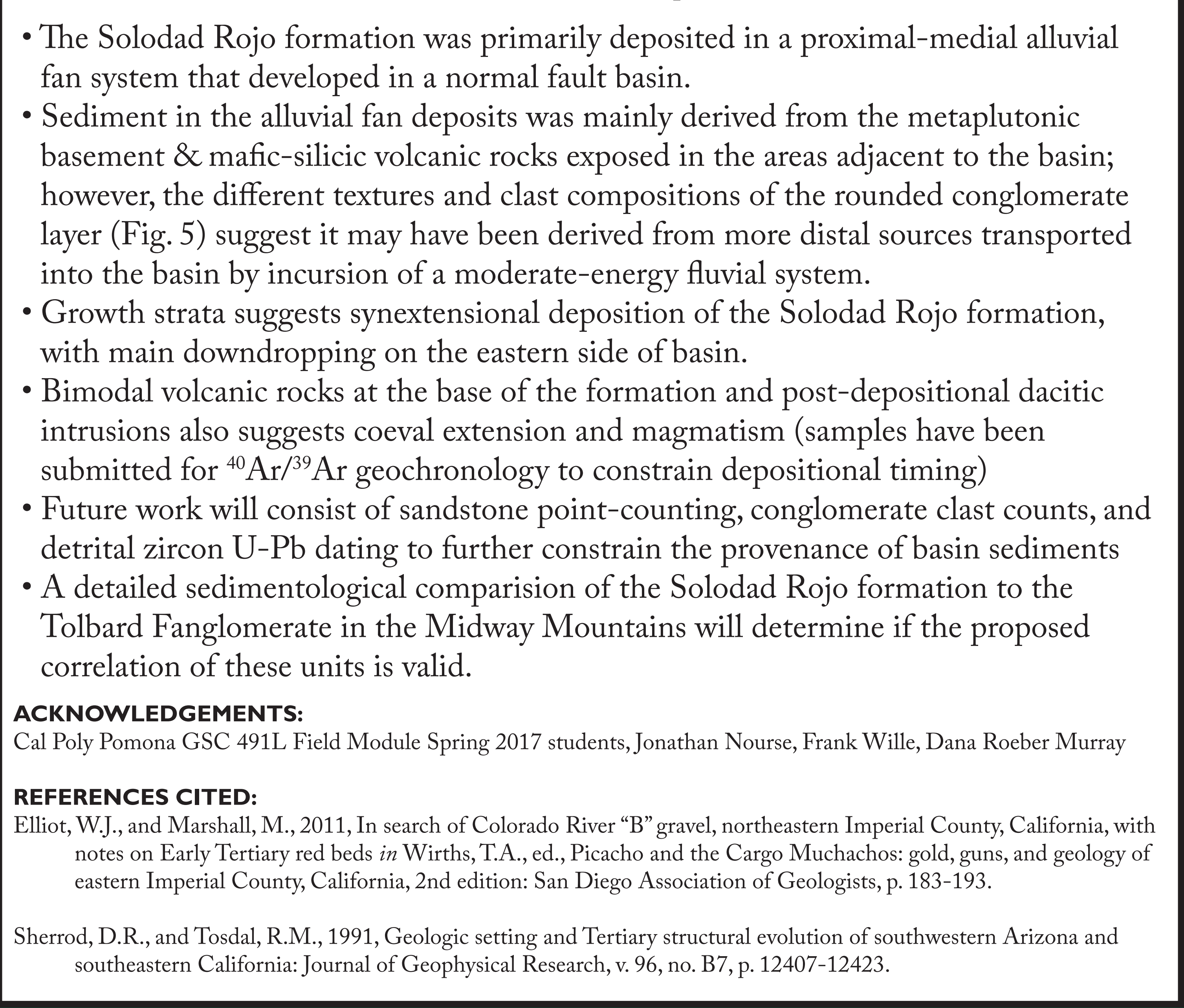

